\title{
Essentials of Online Education during Covid 19 Pandemic, Its Problems and Prospects: An Analytical Study
}

\author{
Trishna Bhuyan
}

\begin{abstract}
Online education is a flexible instructional delivery system that encompasses any kind of learning through internet by using various devices like-computers, laptops, smart phones via different platform like-Zoom, Google Meet, Microsoft team etc. Since March 2020 the entire world comes under covid19 pandemic. The situation was gradually worse day to day. So to meet up the need and demands of educational field we need to change teaching pedagogy, teaching platform, teaching Method etc.

Index Terms - Covid -19 Pandemic, Online Education, Problems and Prospects.
\end{abstract}

\section{INTRODUCTION}

Online education is a flexible instructional delivery system that encompasses any kind of learning through internet by using various devices like-computers,laptops,smart phones via different platform like-Zoom, Google Meet, Swayam, Microsoft team etc. Here teaching can be imparted at anytime, anywhere, anyhow. Teaching is more flexible. It is open and wide in nature. In online education no on campus or physical classes are being allowed.

\section{SIGNIFICANCE OF THE STUDY:}

Since mid time of the March 2020 the entire world comes under covid19 pandemic. The situation was gradually worse day to day. Due to which educational institutions were remain closed for a long time (approximately march $16^{\text {th }} 20$ to Sept. $21^{\text {st }} 20$ ). So to meet up the need and demands of educational field we need to change teaching pedagogy, teaching platform teaching Method etc. Society is changable, so we must ready to accept the changeable situation. This COVID 19 pandemic gives us a new platform to teaching and learning. We need to change our education system from 'chalk and talk' to virtual world. Evaluation also converted to formative, comprehensive online evaluation instead of 'pen and paper'. There are numbers of platform like-zoom, Google meet, Microsoft team, Jio Meet etc, through which teaching learning can be imparted. These online courses give students full control over their own learning They have to learn according to their own choice and pace. During this pandemic this online education has give us a good platform through which teacher educator and students have getting the opportunity to sharing their ideas views and experiences. There are mainly two types of method of teaching which is popularly going on like Synchronised and Asynchronies'. In synchronised method of teaching through zoom link live of teaching learning is possible where students have together at same time From different places during same period of time if they have doubt any E-contents they will get the opportunity to discuss it thoroughly. Here students who are getting connected can learn and rest are unable to see or learn after completion of the live. In Asynchronies where teacher educator have prepared their materials by audio or video form and upload it in their website where students have able to see the materials when they want to see and learn. As formal physical teaching learning is not possible during this pandemic so online teaching learning is best practice here.

\section{METHODOLOGIES}

Paper has been made on the basis of observation method. This paper is analytical in nature. Data are based on primary data. Data

has been analysed by qualitatively. The researcher attended numbers of webinars during this lockdown period and also meet some rural students and finally whatever observed on online education are trying to present here. The investigator also visited some rural institution also to observe the situation. So by this paper an attempt has been made to present all findings briefly.

\section{RESEARCH QUESTION}

What are the challenges and prospects of online education? And how we can able to overcome it?

\section{OBJECTIVES OF THE STUDY}

1. To know about the online education and its necessity.

2. To know challenges of online education.

3. To know prospects of online education.

4. To provide remedial measures 


\section{INTERPRETATION OF DATA}

\section{OBJECTIVE WISE ANALYSIS HAD BEEN DONE IN BELOW:}

\section{A. TO KNOW ABOUT THE ONLINE \\ EDUCATION6.1.TO KNOW ABOUT THE ONLINE EDUCATION AND ITS NECESSITY:}

Online education is a education through which students can be connected digitally via internet connection by using some devices like laptop computers and smart phones. There are some platforms of online teaching like- Google classroom, Microsoft team, Zoom, Google meet etc.

During the Covid 19 pandemic, to meet the needs of the students it is most important to provide online education. Because now a days it is not possible to provide formal physical education to the students. They have face number of problems on their leanings. So to maintain their daily reading writing it is necessary to takes place an additional teaching learning system. In this context online education has taken place, where students are no need to come to the school/colleges and universities. They can learn from their home in a safety manner.

\section{B. TO KNOW THE CHALLENGES OF ONLINE EDUCATION}

1. DIGITAL DIVIDE: Digital divide is major challenge of online education systems. Some students have the laptops, computers, and smart phones with good network connections but some haven't even a mobile phone also. Here students having laptop, Smartphone, network connections are greater beneficial than without having computers laptops etc. By using this system rich are going to much richer and poor are going to much poorer as far as their academic achievement is concerned.

2. INDIVIDUALISED ATTENTION: It is most difficult to give individual attention to the students and to communicate effectively as like as formal education system.

3. ACCESSIBILITY OF INFRUSTRUCTURE: Infrastructure plays an important role to provide effective teaching. Students don't pay any attention to come to school or colleges without having good infrastructure. Regarding online education all educational institutions are not able to access the suitable infrastructure. They have no sufficient laptops, poor network connections, not availability of electricity etc.

4.POOR NETWORK CONNECTION: There are some educational institutions which are at remote areas they have not able to facilitate with a good network connection. In higher educational institutions most of the students are scattered in different places. Here some students are habited in a remote area where they have poor network connection. So in this context they unable to do online classes properly.

5. NECESSECITY OF A DEVICE: To access online education to all each and every student need to a device likeLaptop, computers, or a smart phone through which they can be connected but there are some students who are very poor they unable to bought this sophisticated devices.

6. CREAT FRUSTRATION: As online classes are going on and there are some students who are well talented in pen and paper method and interested to read and write properly but as he is poor in terms of money he unable to buy this type of sophisticated devices then he/she may become frustrated even they might be committed suicide also.

7.INTERNET CONNECTION: To provide online teaching and learning Internet Connection is must nessessery. In this context question must be arise how much students are able to use internet with their devices. Devise itself is costly and also every month 300 or more than 500 rupees internet pack using is not possible for them. Primary and Secondary students facing lots of problems regarding this.

8. USING APPS: Apps are most costly as students are unable to buy it and free apps are not properly worked.

9 .DIGITAL LITERACY: More than 90\% of the population is digitally illiterate. They even don't know to operate the computers properly.

10. QUALITY CONTROL: To some extent quality is deteriorate. Because materials are avaialabe on online. Here students are unable to find out which materials are more authentic and relaiable.

11. SAFETY AND CYBER SECURITIES: It is necessary to give importants on safety and syber securities. Lots of cyber crimes are happening on day day. Hacker can easily hacked the facts. It is most crucial to keep safe.

12. E- CONTENTS: E- contents are available. But the authenticity reliability and validity of the e- contents are noticeable. So It should be keep in mind to authentification of sourses from where material are collected.

14. IT IS QUIET PASSIVE: In online learning students are not actively involved. Here teachers are provide their material in one time and students have to read according to their own pace. In live class though there is a scope for questioning directly but due to lack of proper knowledge they unable to do it and keep themselves passive.

15. INSTITUTIONAL ROUTINE BASED COULD NOT FINE: It is not possible to maintain the regular class routine as like as formal physical classes. Some teachers have done regularly two or three classes. But majority of teachers are unable to manage it.

16. PEN AND PAPER EXAMINATION ARE PROHIBITED: In online learning pen and paper examination is prohibited. As most of the questions are MCQ type so all-round development of personality of the students are not possible here. Creativity of the students are not measures here.

17. CHALK AND TALK METHOD ARE REMOVING: In online learning chalk and talk method are remove. Here power point presentation, audio video etc are provided.

18. NOT POSSIBLE TO OBSERVE BEHAVIOR OF THE STUDENTS: In online learning students behavior is not observed directly as like as physical classes.

19. NO PROVISION FOR INTERNAL ASSESSMENT: In online teaching Internal assessment is not done adequately. It is as like as assessment of Distance learning.

20. Effect on physical health of both students and teachers such as Eye Sight, Lower back Pain, Stiffness of Neck.

21. EFFECT OF MENTAL HEALTH OF BOTH STUDENTS AND TEACHERS STRESS: Due to unable to 
receive online classes some students might have frustrated.

22. OVERLAPPING OF PERSONAL AND PROFESSONAL, OFFICIAL TIME: No fixed time for professional and personal time. So work overlapping is here.

23. LACK OF PEER INTERACTION: Peer interaction is most essential for the students. They have learned lots of knowledge from their peer. In online education they unable to meet their peers.

24. CO-CURRICULUM ACTIVITIES: Co- Curricular activities like sports, dancing, music etc are not properly conducted on online mode.

25. PRACTICAL COURSES: Problems are arises to provide practical courses on online mode. In science subjects like Physics, Chemistry a well equipped laboratory is necessary to properly conduct the practical work; In this regard online education is not suitable.

\section{FUTURE PROSPECTS}

1. Blended Learning would be taken place in teaching learning process in near future.

2. E-Resources are available at various web portals. Students have to just searching the material a huge numbers of materials are come out.

3. Getting a platform to meet the different expert across the world. Students able to meet the different expert on different field sitting from their home. If they face any problem they can ask any expert at that field of the world.

4.New programmers like BA in liberal arts are being designed where the fundamentals of varied disciplines like, Psychology, Philosophy, Political science, Economics, Journalism, English, Literature, Business Studies, Advertising, Finance, Marketing are offered to the students. Redesigning course curriculum, and method of teaching.

5. Such types of learning can empowered the students think to rethink.

6. Multiple Courses are offered, so that a holistic,interdisciplinary education can be developed . Which can helps to develop all round personality, and making the students deserving for the Changing era of the society.

7. Students are able to know about the global scenario on educational field and it's allied Sectors.

8. Conduct virtual talk sessions. This online education is necessity on virtual platform. Here Students are able to learn how to conduct classes virtually.

9. Students have to self motivated. They are engaging to learn by themselves. Here they do hard work.

10. Such education can develop a sense of ownership and thought leadership among the students.

11. They able to develop such skills like learning to learn unlearn and re-learn.

12. The pandemic also an opportunity to remind ourselves of the skills students need in this unpredictable world such as informed decision making, creative problem solving, and adaptability.

13. Classroom should not be only location, Teacher the only facilitator and text book not the only medium for a resilient school system.

14. Technology only has to be a small campus of an effective blended learning activity when considering the strategies, elements, and models listed above.
15. Anatomy is emphasized to better democratize the experience where learners explore and demonstrate high levels of understanding related to concepts and constructing new Knowledge.

\section{FINDINGS OF THE STUDY}

It has been found from the whole study-

Challenges of online education-

1. Digital divide.

2. Individualized attention.

3. Accessibility of infrastructure.

4.Poor network connection.

5. Necessecity of a device.

6. Create frustration.

7. Internet connection.

8. Using apps.

9. Digital literacy.

10. Quality control.

11. Safety and cyber securities.

12. E- contents.

14. It is quiet passive.

15. Institutional routine based could not fine.

16. Pen and paper examination are prohibited.

17. Chalk and talk method are removing.

18. Not possible to observe behavior of the students.

19. No provision for internal assessment.

20. Effect on physical health of both students and teachers such as eye sight, lower back pain, stiffness of neck.

21. Effect of mental health of both students and teachers stress.

22. Overlapping of personal and professional, official time.

23. Lack of peer interaction.

24. Co-Curriculum activities.

25. Practical courses.

Prospects of online education:

1. Blended Learning would be taken place.

2. E-Resources are available at various web portals.

3. Getting a platform to meet the different expert across the world.

4.New programmers like BA in liberal arts are being designed.

6. Empowered the students think to rethink.

7. Multiple Courses are offered, so that a holistic, interdisciplinary education can be developed.

8. Students are able to know about the global scenario on educational field and it's allied Sectors.

9. Conduct virtual talk sessions.

10. Students have to self motivated.

11. Such education can develop a sense of ownership and thought leadership among the students.

12. They able to develop such skills like learning to learn unlearn and re-learn.

13. Helps students to such as informed decision making, creative problem solving, and adaptability.

14. Classroom should not be only location, Teacher the only facilitator and text book not the only medium for a resilient school system.

15. Technology only has to be a small campus of an effective blended learning activity when considering the 
strategies, elements, and models listed above.

16. Anatomy is emphasized to better democratize the experience where learners explore and demonstrate high levels of understanding related to concepts and constructing new knowledge.

\section{SUGGESTIONS FOR REMEDIAL MEASURES}

1. Accessibility of infrastructure in educational institutions.

2. Re- arrangement of classroom

3. Equipped with digital classroom

4. Good network connection

5. Provide electricity connections to all remote areas so that educational instititutions of remote areas can be included.

6. Provide Good and free internet connections to all educational institutions.

7. Should availability of laptop and computers in schools/colleges/universities.

8. Create awareness on online education among the students.

9. Provide practical classes on how to do online classes in Google meet, zoom or any other apps.

10. Some students don't know to operate the computers, in this context skills should be provided to them so that they can learn to operate the computers.

11. Apps should be free of cost. Because students are unable to pay for these apps.

12. Students must be self-motivated in online learning.

13. Time management skills are most essential for online classes.

\section{CONCLUSION:}

Change is the ultimate nature of the society. According to the needs and demands of the time and society we must have to change ourselves. Though online education has some challenges yet we have to ready to accept it. Because everything has positive and negative aspect. Practice makes a man perfect. We have to practice it well so that existing problems can be removed and provide a healthy and congenial environment to the students to read and write well with a virtual platform.

\section{REFERENCES}

[1] Cooperman, Larry.(2018) The Art of Teaching online, How to start and How to Succceed as an online Instructor. Chandos Publishing, 50 Hampshire street, $5^{\text {th }}$ floor, Cambridge ,MA 02139, United States.

[2] Smith, Peter Plymton.(2018). Free Range Learning in the Digital Age: The Emerging Revolution in college, Career, and Education. Select books,inc., New York. ISBN- 978-1-59079-484-5.

[3] FDP on Aspects of pedagogical re-design and online teaching learning process organized by Dhemaji college, Dhemaji Assam.

[4] Webinar on Importance on online education during Covid 19 pandemic organized by Chaiduar College Gohpur, Assam.

[5] Sun, A.,\& Chen, X.(2016).Online Education and its Effective practice: A research Review. Journal of Information technology Education: Research, 15, 157-190.

[6] Nguyen, Tuan(2015).The Effectiveness of online learning: Beyond No Significant Difference and Future Horizons. MERLOT Journal of online learning and teaching, 15,309-319.

[7] Palvia, S., et.al.(2018).Online education: Worldwide status, challenges, trends, and implications. Journal of global information technology management, 21: 4,233-241. 